\title{
A global model to forecast coastal hardening and mitigate associated socioecological risks
}

\author{
Oliver Floerl $\mathbb{1}^{1 凶}$, Javier Atalah', Ana B. Bugnot $\mathbb{1}^{2,3}$, Mitchell Chandler ${ }^{1,6}$, Katherine A. Dafforn $\mathbb{1}^{4}$, \\ Lisa Floerl' ${ }^{1}$ Anastasija Zaiko ${ }^{1,5}$ and Robert Major'
}

\begin{abstract}
Around the world, coastal urbanization continues to replace natural marine habitats with engineered structures, resulting in wholesale changes to shallow-water ecosystems and associated socioecological impacts. This process is expected to continue over the coming decades. The development of meaningful strategies to minimize future impacts requires an understanding of the rate at which 'coastal hardening' will take place regionally. Here we show that coastal infrastructure has replaced more than half $(52.9 \pm 4.9 \%)$ of the coastline associated with 30 global urban centres. The regional extent of coastal hardening is explained by eight predictor variables associated with shipping, boating, regional economies, populations and coastline length. Using a case study approach, we forecasted a 50-76\% expansion of coastal infrastructure over a 25-year period. Our model can aid decision-makers to anticipate increases in coastal hardening, supporting identification and management of future threats to coastal ecosystems alongside social, economic and cultural objectives.
\end{abstract}

$\mathrm{n}$ urbanized coastal areas around the world, seawalls, breakwalls, wharves, piers, pontoons and other structures ('coastal hardening') have replaced rocky reefs, sandy beaches, mudflats and mangroves. This process has been driven by the development of civic infrastructure, recreational and commercial shipping facilities, and the need for coastal protection ${ }^{1,2}$. Globally, the present (2018) footprint of engineered coastal and offshore structures (including ports, energy extraction infrastructure and telecommunication cables, among others) is estimated to be at least $32,000 \mathrm{~km}^{2}$, probably representing an underestimate ${ }^{2}$.

Engineered coastal structures have very different physical characteristics than the natural habitats they replace, often resulting in an extensive reduction in intertidal and shallow subtidal areas, and shifts from soft sediment to hard substrates and from natural (that is, rock, sand) to artificial (that is, concrete, plastic, steel) substrates ${ }^{3,4}$. These shifts can drive dramatic changes in functional profiles, productivity and ecosystem service provision of ecological communities $^{5,6}$, with severe associated impacts. For example, the 'trophic footprint' (energy consumed) of $1 \mathrm{~m}^{2}$ of invertebrate-dominated engineered structures can negate the primary production of up to $130 \mathrm{~m}^{2}$ of surrounding coastal waters ${ }^{7}$. Globally, an estimated 1.03.4 million $\mathrm{km}^{2}$ of seascape has been modified by the installation of engineered coastal structures ${ }^{2}$.

Coastal hardening can also exacerbate the establishment and spread of marine non-indigenous species (NIS $)^{4,8,9}$. Ports and marinas associated with coastal centres worldwide are vast artificial environments that represent important nodes in complex maritime transport networks, acting as sources and recipients of marine NIS $^{10}$. These networks connect domestic and international coastal environments, including those associated with high ecological, economic, societal and cultural value ${ }^{11-13}$. Globally, the spread of marine NIS has contributed to dramatic, often irreversible ecological changes to coastal ecosystems ${ }^{14}$.

Coastal ecosystems are also heavily impacted by population growth. Substantial levels of future growth are expected and will be accompanied by additional coastal hardening, particularly in areas that require protection from the impacts of climate change ${ }^{15-17}$. These congested coastal spaces will increasingly require spatial planning and management to ensure a balance between ecological, economic and sociocultural objectives ${ }^{18}$. The ability to forecast the likely expansion of coastal infrastructure at the scale of regional jurisdictions or other spatial units would enable planners and decision-makers to anticipate potential impacts relating to habitat loss, changes in species pools, ecosystem services and social and cultural values, and develop proactive mitigation strategies ${ }^{19,20}$. A tool for this does not presently exist.

Here, we mapped coastal hardening associated with 30 international urban centres and, using machine-learning algorithms, developed a model to forecast the regional expansion of 4 globally common coastal infrastructure types. We applied this model to New Zealand as a case study location and show the model's utility for anticipating regional distributions and future hotspots of socioecological risks over a 25 -year period.

\section{Results}

We quantified the present-day extent (linear $\mathrm{km}$ ) of coastal hardening associated with the regional coastlines of 30 global urban centres (Fig. 1). Coastal infrastructure accounted for approximately half $(52.9 \pm 4.9 \%$; mean \pm standard error $)$ of the total regional coastline (up to $860 \mathrm{~km}$ per centre) around the locations examined (Fig. 2). Breakwalls were the most abundant type of coastal infrastructure ( $61 \pm 3 \%$ of total regional infrastructure), followed by pontoons $(14.5 \pm 2.4 \%)$, wharves $(14.1 \pm 1.5 \%)$ and jetties $(10.7 \pm 1.3 \%)$. Overall, the maximum extents of breakwalls, pontoons, wharves and jetties found at any one study location were $254 \mathrm{~km}, 66 \mathrm{~km}, 74.5 \mathrm{~km}$ and $138 \mathrm{~km}$, respectively (Fig. 2). Owing to their construction away from the shore, jetties and boating pontoons add 'new' rather than replace existing coastline (Supplementary Fig. 1). Across the locations mapped, these structures had added $13 \pm 1.9 \%$ to the original (natural) coastline.

'Cawthron Institute, Nelson, New Zealand. 2University of Sydney, Sydney, New South Wales, Australia. ${ }^{3}$ Sydney Institute of Marine Science, Mosman, New South Wales, Australia. ${ }^{4}$ Macquarie University, Sydney, New South Wales, Australia. ${ }^{5}$ University of Auckland, Auckland, New Zealand. ${ }^{6}$ Present address: Scripps Institution of Oceanography, University of California San Diego, La Jolla, CA, USA.凶e-mail: oliver.floerl@cawthron.org.nz 


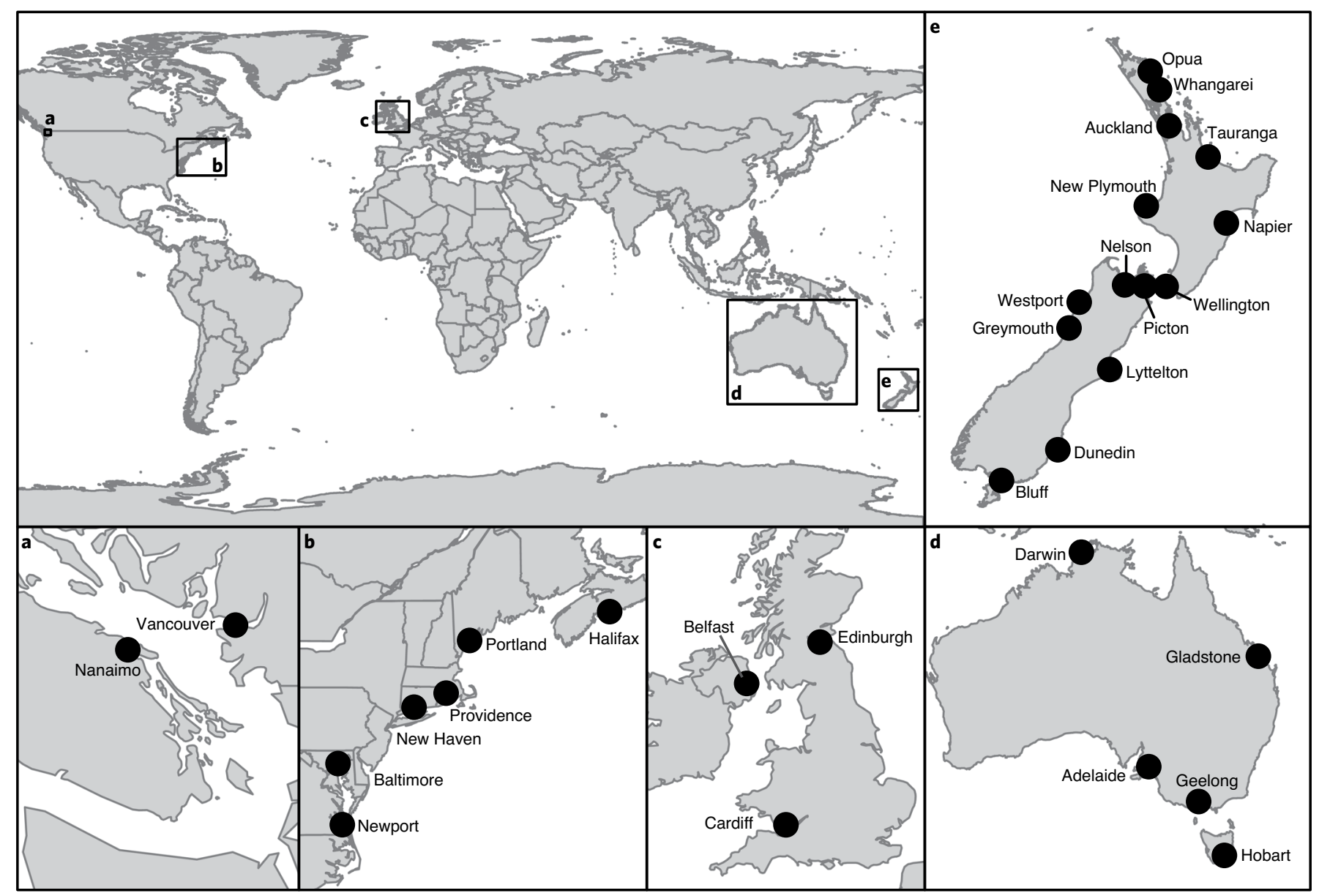

Fig. 1 | Costal hardening extent determined for $\mathbf{3 0}$ global urban centres. a-e, Insets provide details on centres examined around North America (a, b), the United Kingdom (c), Australia (d) and New Zealand (e). Maps are from ArcGIS Living Atlas of the World.

Predictors of coastal urban infrastructure. We used machine-learning algorithms to examine the utility of 25 candidate variables associated with regional economy, population, trade and geomorphology as predictors of present-day coastal hardening (Table 1). The random forest 'feature selection' algorithm identified nine important or tentative variables, and these were used to develop a predictive model. Eleven variables were identified as unimportant, including four variables relevant to the effects of climate-induced increases in storm surges and sea-level rise (tidal range, per cent sand content of shoreline, per cent mud content of shoreline and mean significant wave height). Five variables were highly colinear (that is, variance inflation factor $>3$ ) and were excluded from subsequent analyses (Table 1 ).

Random forest models fitted to the global dataset, comprising the 9 important or tentative predictors, returned 8 final variables that together best explained the present-day extent of coastal hardening across all 30 locations. For the model that incorporated all infrastructure types, these were, in decreasing order of relative importance: port vessel visits, number of marinas, port revenue, regional gross domestic product (GDP), council population, total coastline length, port cargo and container throughputs (Table 1 and Supplementary Box 1). The relative importance of predictors varied slightly between models for specific infrastructure types (that is, breakwalls, pontoons, wharves and jetties) but generally shipping- and boating-related variables had the highest relative importance. Model training achieved good correspondence between observed and predicted values for all models
( $R^{2}$ of $\left.0.86-0.92\right)$. Final model fit was good overall, with root mean squared error equating to approximately $10 \%$ of the data range of the response variables. The best-performing models were derived for total coastal infrastructure extent and extent of pontoons and wharves, accounting for up to $54 \%$ of the variation in the data (Supplementary Box 1).

Forecasting future coastal hardening with a New Zealand case study. Regional economic, population and trade growth scenarios (25-year horizon) were applied to the final random forest models (Tables 1 and 2; Supplementary Data 1) to forecast the extent of hardening across New Zealand's urban centres. The models predicted a total increase of $243 \mathrm{~km}$ (low-growth scenario) to $368 \mathrm{~km}$ (high-growth scenario) in coastal infrastructure by 2043 for New Zealand's coastal urban centres combined, representing a 49-76\% increase relative to 2018 (Fig. 3). The greatest absolute increases were predicted for breakwalls (104 to $161 \mathrm{~km}$ under low- to high-growth scenarios, respectively), equating to a relative expansion (relative to 2018 extent) of $31-48 \%$. The highest relative increases were predicted for shipping wharves (125-191\%) and jetties (119-197\%), although these involve considerably smaller absolute expansions (44-75 km; Fig. 3a).

The greatest proportion $(67 \%)$ of the total domestic increase in coastal hardening was predicted for Auckland, Tauranga and Lyttelton harbours, accounting for 14-26\% of expansions in breakwalls, $19-42 \%$ in jetties, $20-26 \%$ in wharves and $11-35 \%$ in pontoons (Fig. 3b). Increases in the extent of coastal hardening by 2043 

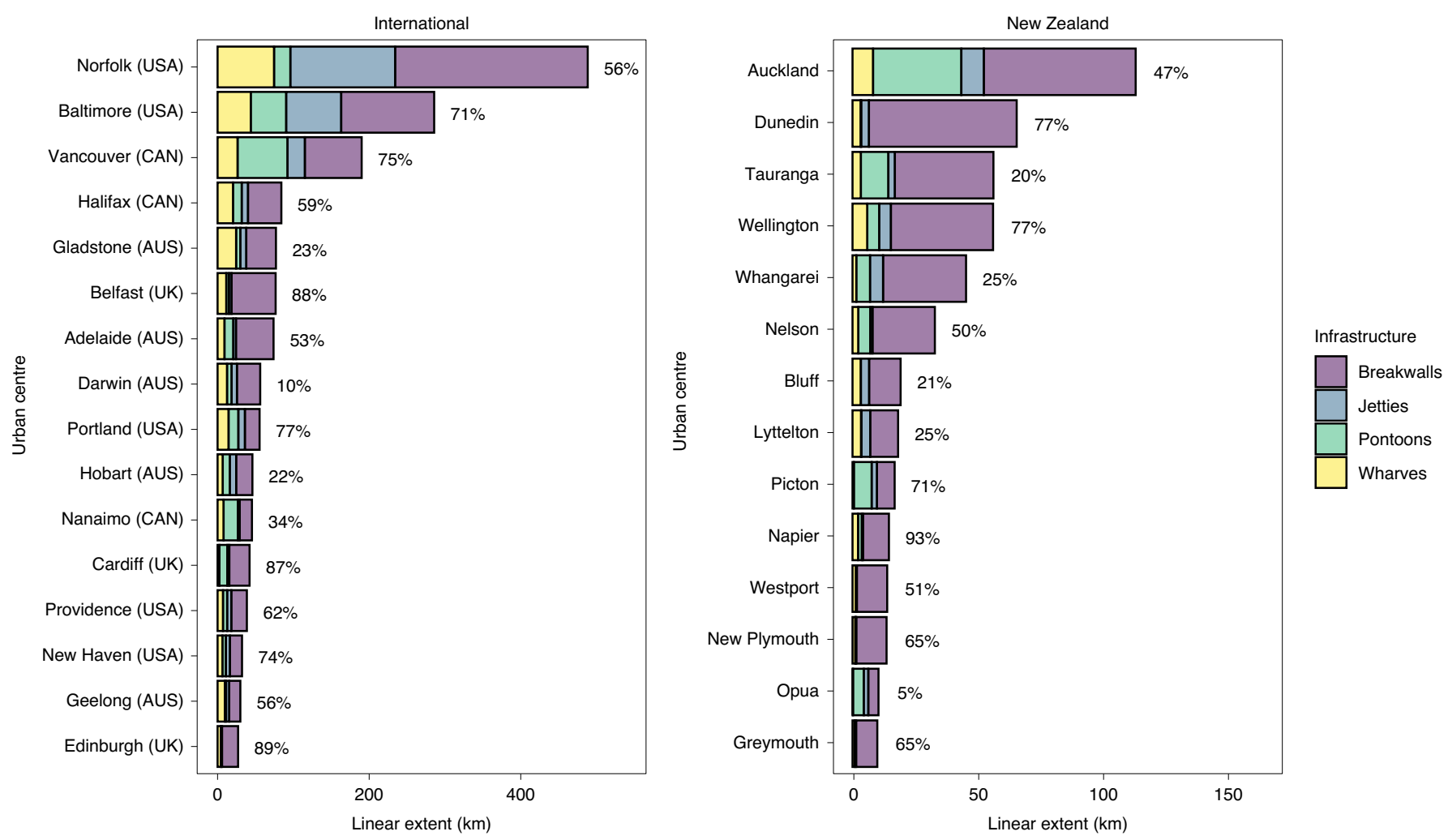

Fig. 2 | Present-day extent of coastal infrastructure associated with 30 international urban centres. Bars represent the coastline distance ( $\mathrm{km}$ ) occupied by each structure type; per cent values indicate the artificial (hardened) proportion of the total coastline associated with the urbanized harbour.

were also forecast for most other urban centres. By 2043, 52-61\% (low- to high-growth scenarios) of the regional coastline associated with the New Zealand case study locations will be artificial (hardened), compared with $35 \%$ in 2018 .

Coastal hardening and NIS risks. Since 2001, between 18 and 66 marine NIS have been detected in coastal waters around New Zealand's urban centres by government-led nationwide baseline survey and targeted surveillance programmes. We found a significant relationship $\left(R^{2}=0.57, P<0.01\right)$ between the 2018 extent of coastal hardening around coastal urban centres and the number of marine NIS detected in each (Fig. 4). Application of the regression model to the 25-year coastal hardening forecast for regions around New Zealand predicted greatest increases in NIS occurrence at Tauranga, Auckland, Lyttelton, Napier and Picton harbours. This outcome is almost identical to (1) our global model's ranked regional distribution of total forecasted increases in coastal hardening and (2) the ranked domestic biosecurity risk scores derived for New Zealand's international arrival ports via state-of-the-art risk models (Supplementary Table 1). There was also good correspondence between our model's predictions and the domestic biosecurity risk scores for the lower-ranking locations.

\section{Discussion}

Our study shows that coastal hardening is consistently extensive around urbanized harbours and estuaries in global locations including North America, the United Kingdom, Australia and New Zealand. On average, over half (52\%, or 2,135 linear $\mathrm{km}$ ) of the total coastline associated with each of the 30 mapped locations is already artificial. We also show that eight variables associated with commercial shipping, recreational boating, regional economic status, population size and regional coastline length can robustly predict the extent of coastal hardening associated with urbanized harbours and estuaries. Variables related to shipping and boating had the highest relative importance.

The construction of novel habitats (jetties and pontoons) has increased the original coastline length by an average of $13 \%$. It was recently estimated that construction of shipping ports around the world (of which there are at least 6,500 ) has replaced $4,500 \mathrm{~km}^{2}$ of coastal habitat ${ }^{2,21}$. In our study, port-related infrastructure represented on average only $14 \%$ of the overall extent of infrastructure associated with each urban centre, while the remainder consisted of civic structures and recreational boating facilities. Together, our study and others ${ }^{2,7}$ have demonstrated the massive extent of natural habitat loss from coastal hardening around global coastlines.

Forecasts developed for a case study location (New Zealand) predict a considerable expansion in the extent of coastal hardening around domestic urban centres over the coming 25 years. Predicted rates of increase appear realistic when compared with historical expansions of coastal hardening recorded in New Zealand over the past 50-80 years (84-127\%; Supplementary Fig. 2) and are consistent with recent strategic assessments by government and industry regarding expected domestic requirements for civic and transport infrastructure ${ }^{22-24}$. Interestingly, variables relevant to the effects of storm surges and sea-level rise were not recognized as important predictors of the present-day extent of coastal hardening. However, climate change and the increasing threat of sea-level rise might drive changes in management focus in the future ${ }^{25,26}$. For locations where this becomes the case, forecasts derived using our model might be conservative, in particular for breakwalls (structures frequently built to stabilize erosion-prone coastlines). Our current model assumes a business-as-usual scenario but understanding and incorporating potential shifts in socioeconomic priorities is an important future refinement as information becomes available.

The socioecological implications of further increases in coastal hardening are considerable. It will result in the loss of extensive 
Table 1 | Candidate predictor variables for coastal hardening and stages of analysis they were used in: exploratory analyses based on New Zealand case study data; development of global predictive model; and final model and forecasting

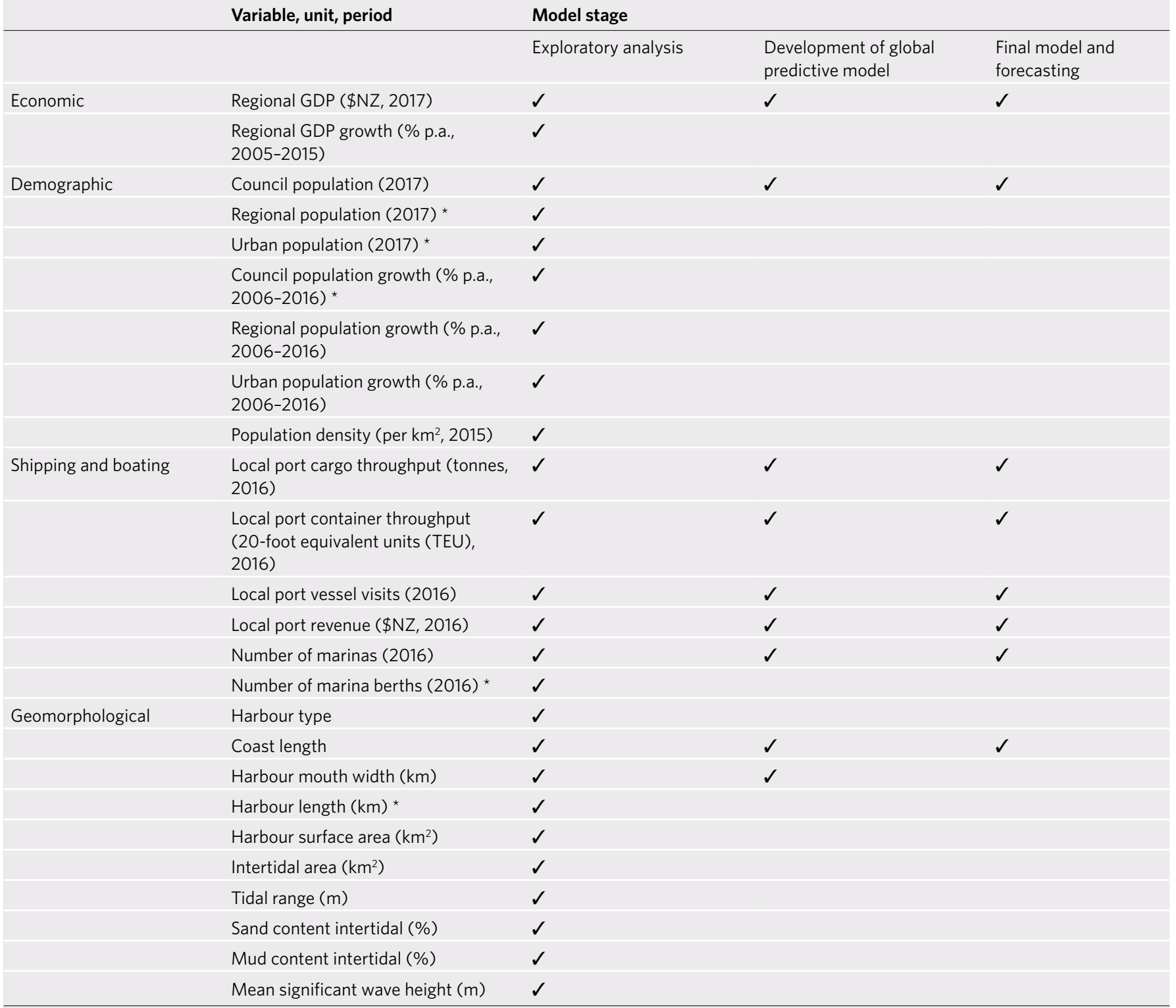

Final models were fitted using government and industry predictions for variables tagged for 'final model and forecasting' (Supplementary Data 1). Variables removed due to collinearity are marked with an asterisk *.

remaining natural habitat (beaches, rocky reefs, mangroves, mudflats and others), with important consequences for shallow-water and coastal ecological communities, trophic processes, nutrient cycling and cultural/spiritual values $\mathrm{s}^{6,13,27,28}$. For example, the capacity of ecosystems to store and degrade nutrients may be reduced through loss of sedimentary habitat ${ }^{5}$, while overall productivity might be enhanced due to the increase of hard substrates and the development of sessile biofouling communities on these. On average, each square metre of global coastal hardening infrastructure features $16.7 \mathrm{~kg}$ of sessile biomass that consumes the energy equivalent of $26 \mathrm{~m}^{2}$ of ocean surface primary production per day ${ }^{7}$. Further increases in the cumulative 'trophic footprint' of coastal hardening will deplete important resources for coastal marine ecosystems already under pressure from other processes such as pollution and harvesting 2,29 .

Further substantial increases in coastal hardening will also facilitate the establishment and spread of marine NIS ${ }^{4,9}$, exacerbating impacts on native ecosystem processes, the operations and productivity of aquaculture and other maritime industries and the integrity of cultural values ${ }^{30-32}$. Our case study models' ranked predictions of (1) the domestic distribution of coastal hardening increases for the coming 25 years ('hardening hotspots') and (2) the associated increases in the occurrence of marine NIS both correspond well to independent modelling of domestic marine biosecurity risk associated with New Zealand's main international arrival ports ${ }^{33}$. This highlights the utility of coastal hardening forecasts for identifying likely future 'hotspots' of NIS establishment, ideally in association with maritime trade models ${ }^{34}$.

Interpretation of forecasts. Our models indicate that regional rates of coastal hardening can be forecast based on present-day values and expected growth rates of only eight variables (port vessel visits, number of marinas, port revenue, regional GDP, council population, port cargo and container throughputs, and total coastline 
Table 2 | Summary of growth predictions used to forecast the potential for regional increases in coastal infrastructure around New Zealand

Predictor type Predicted annual growth rates (\% p.a.) to 2043 (regional ranges for 14 coastal centres)

\begin{tabular}{lll}
\hline Low growth & $\begin{array}{l}\text { Moderate } \\
\text { growth }\end{array}$ & High growth \\
\hline & &
\end{tabular}

Ports and shipping

\begin{tabular}{llll} 
Cargo & $0.70-1.90$ & $0.85-2.05$ & $1.00-2.30$ \\
Containers & $0.70-2.50$ & $0.85-2.80$ & $1.00-3.20$ \\
Vessel visits & $0.70-2.10$ & $0.85-2.40$ & $1.00-2.70$ \\
\hline Port revenue & $0.70-2.10$ & $1.94-2.40$ & $1.00-2.70$ \\
Marinas & $0.25-0.35$ & $0.40-0.47$ & $0.55-0.65$ \\
Council population & -0.90 to & -0.20 to 1.50 & $0.30-1.90$ \\
growth & 1.00 & & \\
Regional GDP growth & $3.18-4.68$ & $4.24-6.23$ & $4.66-6.86$
\end{tabular}

Data sources and exact figures for regional growth estimates in low-, medium- and high-growth scenarios are included in Supplementary Data 1.

length). Collation of these data should be very achievable for most planning and management agencies around the world. Forecasts of regional rates of coastal hardening are best interpreted as potential for infrastructure expansions of a predicted magnitude. Depending on geological, industrial, political and societal factors this potential for growth may be realized in different ways: via (1) construction of new infrastructure, (2) urban expansion away from the coast, (3) increasing the efficiency of existing infrastructure or (4) outsourcing particular activities or services to other regions ${ }^{23,35}$.
This interpretation allows for the consideration of location-specific circumstances when translating regional forecasts into actual expected growth for planning and mitigation purposes. For example, the current (2018) proportion of artificial coastline for the 30 urban centres examined varied from $5.4 \%$ to $83 \%$. Those at the upper end of this range may be more likely to rely on strategies (2), (3) or (4) (above), while strategy (1) may be feasible for centres with larger proportions of remaining undeveloped coastline.

Minimizing the impacts of continued marine urban sprawl. Marine spatial planning (MSP) aims to manage ocean spaces by balancing multiple stakeholders and objectives. MSP is a growing field given the increasing global importance of the Blue Economy ${ }^{36}$ and the multiple pressures threatening marine systems ${ }^{37}$. Coastal development has historically occurred primarily in response to socioeconomic objectives, with less emphasis on ecological or cultural considerations $^{38}$. MSP together with innovations in multifunctional design and biosecurity has the potential to manage future spread of built structures in the oceans to address different stakeholder needs $s^{18,39,40}$ and provide options for reconciliation of socioeconomic and ecological priorities ${ }^{38}$. The model developed here provides an important tool for MSP decision-making by enabling forecasts of regional rates of coastal hardening. This information, combined with innovations in ecological engineering, biofouling control and species monitoring tools, could support improved spatial risk assessment for conservation and biosecurity. Three important available avenues are discussed below.

Designing multifunctional coastal infrastructure. Multipurpose offshore platforms are becoming more widely implemented, with energy and aquaculture combining to co-locate systems and maximize benefit from a smaller ocean footprint ${ }^{41}$. A recent assessment ${ }^{38}$ proposes seven functions (or goals) that could be

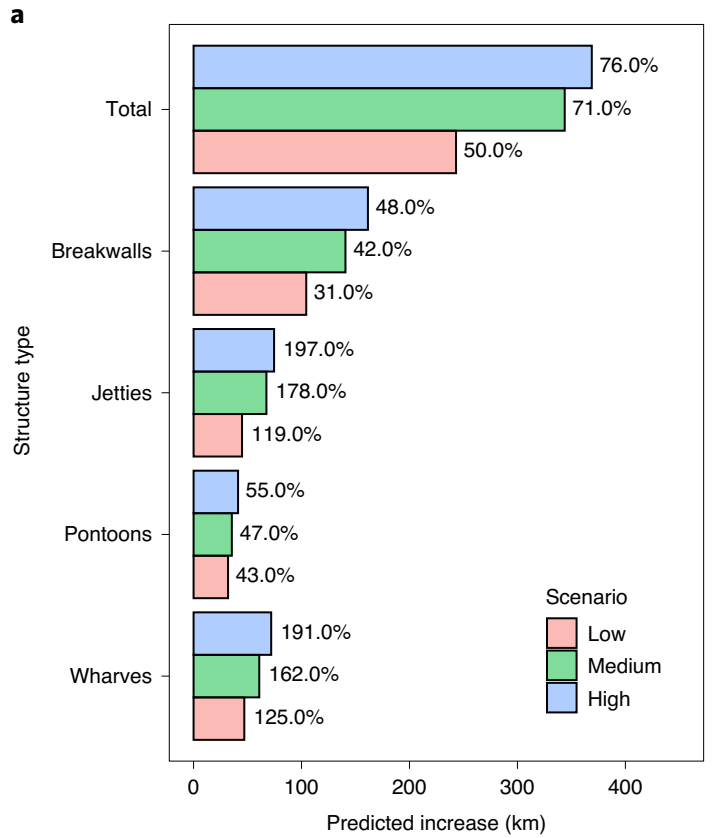

b

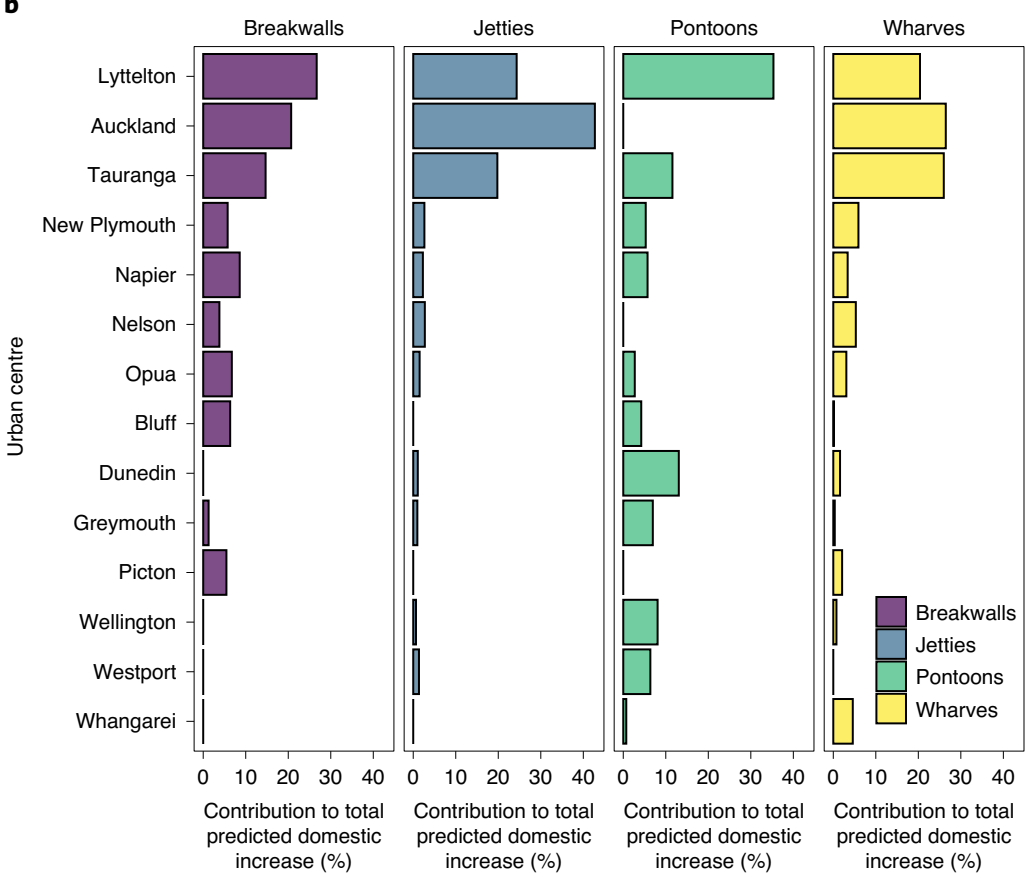

Fig. 3 | Coastal hardening forecast for New Zealand. a, Forecasted increase in the extent of coastal infrastructure associated with New Zealand's urban centres by 2043. Bars represent predicted absolute increase according to low-, moderate- or high-growth scenarios; percentages indicate predicted increase relative to 2018 . b. Regional distribution of the forecasted change in coastal hardening extent for the New Zealand case study locations by 2043 (medium-growth scenario). Bars represent the average mean contribution of each regional centre to the total predicted domestic increase. 


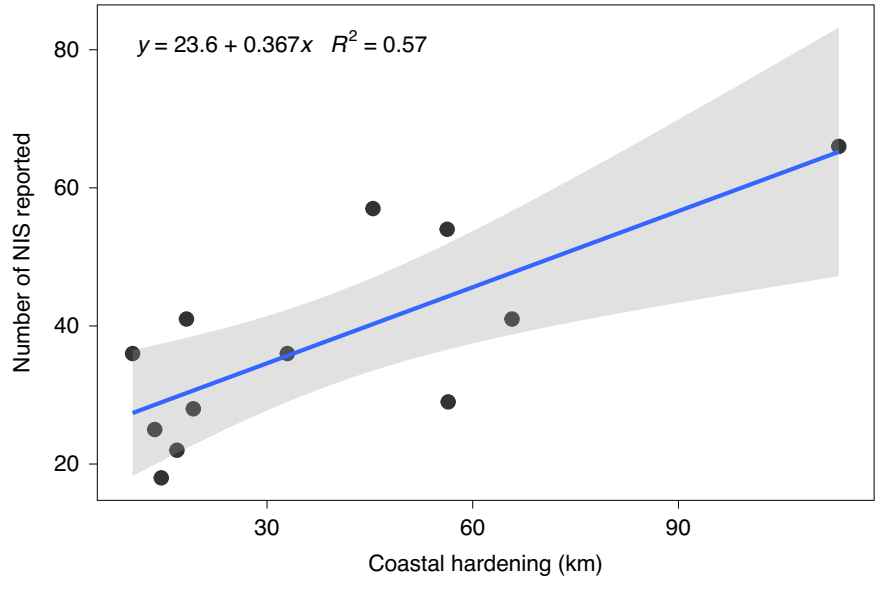

Fig. 4 | Relationship between present-day extent of coastal hardening in New Zealand case study locations and the numbers of NIS occurring around these locations. Black circles depict case study locations; regression line (blue line) and 95\% confidence intervals (shading) are overlaid.

incorporated into the design of coastal structures in addition to traditional engineering functions: (1) maintenance of local native biota; (2) restoration of local biodiversity; (3) maintenance of regional biodiversity; (4) provision of educational and recreational opportunities; (5) maintenance of water quality; (6) facilitation of carbon storage; and (7) support of aquaculture and food production. We propose an additional, eighth function: the enhancement of cultural or spiritual values, where the design of infrastructure aims to restore or increase populations of species valued for traditional gathering, or to compensate for the impacts on other cultural values ${ }^{13}$. While the incorporation of multifunctionality into infrastructure development may not be able to mitigate trophic footprints or direct construction impacts, there is the potential to reduce the spatial extent of development if some functions are combined and offset impacts via the provision of ecological, societal, cultural or economic services ${ }^{18,42}$.

Minimizing NIS populations on coastal infrastructure. Submerged coastal infrastructure, in particular structures associated with shipping and boating facilities, are attractive substrates for NIS and often function as hotspots for invaders ${ }^{4,8,10}$. Our model highlighted the potential for substantial future increases in the spatial extent of these structures (pontoons, wharves and jetties) around our case study area, highlighting a need for innovation in intervention measures. Novel strategies to minimize the establishment of NIS on coastal infrastructure include environmentally friendly antifouling solutions such as surface treatments, air-bubble based protection technology or augmentative biocontrol ${ }^{43-46}$. Reducing resident populations of problem organisms on key infrastructure will limit propagule production and colonization rates of locally moored vessels and, thereby, the frequency with which NIS or other problematic species are spread to further destinations.

Development of improved monitoring tools. Improved surveillance and monitoring tools can enhance our ability to detect adventive populations of marine NIS or other harmful (for example, pathogenic) species. Revolutionary advances continue to be made in the development, operationalization and cost-effectiveness of molecular tools for environmental monitoring and assessment ${ }^{47-49}$. Wide and effective implementation of such tools and prospective automation of molecular-based detections can help mitigate some of the risks associated with 'unprotected' infrastructure. Integration of technologies such as those described above with the model developed in this study could help prioritize locations where interventions are best directed.

Summary. Marine urban sprawl is expected to continue around the world ${ }^{2,28}$. The modelling framework described here facilitates forecasting of regional rates of increase in the world's most common types of coastal infrastructure based on economic, population, transport and geomorphological predictors, and the identification of likely hotspots of future NIS incursions. The model can be adapted by global planners and decision-makers to manage increasingly congested ocean spaces more sustainably and to focus environmental solutions on prioritized structures and areas.

\section{Methods}

We quantified present-day coastal hardening in 30 global urban centres and developed a model to forecast regional increases in coastal hardening, using New Zealand's urban harbours and estuaries as a case study. This model was developed based on observations from global coastal centres, using a five-step approach (Supplementary Fig. 3). First, we quantified the present-day extent of coastal hardening associated with 30 global coastal urban centres. Second, exploratory analyses for 14 of these locations were used to identify predictors of coastal hardening from a larger set of candidate variables. Third, data for the predictor variables identified in step 2 were collected for the remaining global locations. Fourth, a predictive model was constructed and validated using the overall dataset. Lastly, the model was applied to forecast coastal hardening for 14 New Zealand coastal centres by 2043 (a 25-year horizon), based on 3 expected growth scenarios for the economic, urban and demographic predictors identified in step 2.

Quantification of present extent of coastal infrastructure. We determined the spatial distribution and extent of coastal infrastructure associated with 30 global coastal centres. To develop a model with wide applicability, we ensured that the urban centres selected represented a large gradient in area, population and economic aspects. By necessity, our selection was also guided by the availability of reliable, high-quality data for predictor variables. Unfortunately, this precluded the incorporation of locations from coastal regions around Asia, Africa and South/Latin America, particularly those within developing nations. Our 30 global centres were located around Australia, New Zealand, the United Kingdom and North America. All centres were situated within protected harbours or estuaries, or protected by coastal islands, and comprised urban/civic, shipping and boating facilities (Fig. 1). The absence of model locations situated in some regions of the world mean that the final model is probably not applicable to all global regions. However, as data for those regions become available, our model can be readily updated to provide benefits for areas currently not included.

Coastlines associated with each of the targeted locations were digitized based on $0.5 \mathrm{~m}$ resolution or higher satellite and aerial imagery (Land Information New Zealand's imagery basemaps, Esri's World Imagery (2014-2018; DigitalGlobe, councils and Marine GeoLibrary)) using ArcGIS Pro (version 2.4.0). Where urban centres extended into coastal areas beyond the harbour's or estuary's entrance, digitization was completed to the jurisdictional boundary. For each location, we mapped the extent of (1) natural coastline and (2) four main types of artificial structure: breakwalls, shipping wharves, jetties and floating pontoons (Supplementary Table 2 and Supplementary Fig. 1). While pontoons are floating structures, they have a stationary footprint and 50-year service lives. Floating marinas are consented as permanent installations and hence included as coastal infrastructure in our study. Geodesic length of each mapped element was calculated using New Zealand Transverse Mercator projection and relevant Universal Transverse Mercator projection zones for international regions. For large structures such as wharves and piers, the outer perimeter was delineated, while smaller structures such as jetties were represented by single lengths. For marina pontoons, the total length included their central walkway and all associated finger wharves. Natural coastline was traced along estimated high tide lines. For the 14 New Zealand locations, the surface area of all natural and artificial coastline elements was also calculated using Land Information New Zealand's bathymetry data and standardized equations (details in Supplementary Box 2). Correlation analysis determined a strong association between linear and surface area extent of coastal artificial structures around New Zealand harbours (Pearson's $r=0.90 ; P<0.05$ ). Based on this correlation, digitization of global model locations quantified only the linear extent of coastal infrastructure.

Choice of case study area. We chose New Zealand as a case study area to identify potential predictors of regional increases in coastal hardening for several reasons. First, it is a maritime and highly urbanized ${ }^{50}$ country featuring numerous coastal centres of varying size located in or around protected harbours and estuaries. Second, New Zealand's economy is heavily reliant on shipping, and it is a popular destination for international and domestic cruising yachts. As such, New Zealand's coastal urban centres generally feature shipping and boating infrastructure, 
which are thought to be strong drivers of coastal development and the spread of non-indigenous marine species ${ }^{2,9}$. Finally, excellent datasets are available for New Zealand relating to a wide range of potential predictor variables for coastal hardening, via resources offered by regional or central government agencies, industry groups or science organisations.

Identification of candidate predictor variables. We identified a total of 25 economic, demographic and geomorphological/environmental variables as potential predictor variables of the present-day extent of coastal hardening (Table 1). These candidate variables were selected because (1) they had been identified as drivers of urban expansion in previous studies ${ }^{15,51}$, (2) they had been identified as key variables for the classification of New Zealand's estuarine and coastal marine environments ${ }^{52}$ and (3) in the case of geomorphological variables, they had direct relevance to expected effects of climate change. Using the 14 New Zealand case study locations, exploratory analyses were then undertaken to identify a constrained subset of potentially important predictors before collecting these data for the remaining global urban coastal centres (Table 1).

Random forest models were the primary statistical technique used to (1) explain present-day extent and (2) predict future growth of coastal infrastructure (below) Random forests are a non-parametric, machine-learning algorithm method that uses classification and regression trees to classify data or make predictions ${ }^{53,54}$. They bootstrap data to construct multiple trees grown with a randomized subset of the predictors and often outperform traditional regression approaches ${ }^{55}$. Two approaches were used to identify the important variables amongst the candidate predictors. First, the relative importance of the 25 candidate variables was examined using random forest 'feature selection' ( $\mathrm{R}$ package Boruta ${ }^{56}$ ) in relation to the present-day extent of (1) the total extent of coastal infrastructure and (2) the extent of each of the four different structure types (that is breakwall, wharf, jetty and pontoon) for the 14 case study locations. This approach utilizes an algorithm designed as a 'wrapper' around the random forest classification algorithm that iteratively removes variables that are proven by a statistical test (based on $z$ scores) to be less relevant than random probes. Secondly, correlations between the remaining variables were then identified using variance inflation factors and sequential removal of predictors with a variance inflation factor $<3\left(\right.$ ref. ${ }^{57}$ ).

Construction and validation of a global predictive model. Data for the 9 variables identified as important predictors in the exploratory analysis (Table 1) were obtained and collated for all 30 global model locations (Supplementary Data 1). Random forest models were then fitted using the $\mathrm{R}$ software packages randomForest $\mathrm{t}^{58}$ and Caret ${ }^{59}$ for the total linear extent $(\mathrm{km})$ of coastal infrastructure and for each of the four infrastructure types. Models were validated using 10-fold repeated cross-validation. Final models were selected based on the root mean squared error, enabling optimal model parametrization regarding number and depth of trees. Final models included 8 predictor variables (Table 1) and were used to forecast the extent of coastal hardening around New Zealand by 2043, a time horizon of 25 years at the time of the analyses.

Forecasting future coastal hardening with a New Zealand case study. Using government (for example, Stats NZ, regional councils and central government agencies), industry (for example, port and shipping companies and representative industry bodies) and financial (for example, banks and economic institutions) publications and databases (Supplementary Data 1), the final models were used to forecast the change in coastal hardening (total extent and extent of the four infrastructure types) around New Zealand based on expected economic, demographic and trade-related information. Forecasting was undertaken for a 25-year time horizon (2043) using low-, moderate- and high-growth scenarios identified from the predictor sources. For many predictors (for example, population increases, economic growth and some shipping trade variables), expected annual growth rates have been published for the modelled time horizon. For some other variables (for example, growth in recreational vessel marinas) published information included past average annual growth rates or shorter-term future growth rates. In those instances, annual compound growth was calculated and extrapolated to the 25-year horizon (Supplementary Data 1). The variance around the forecasted coastal infrastructure extent was calculated using infinitesimal jack-knifing. This technique works by omitting each observation (leave-one-out) and rerunning the estimate with the remaining data. Variances were square-root transformed to provide a standard deviation for each data point (Supplementary Box 1).

The outlook by industry and government at the time of model development suggested small to considerable annual growth relating to ports $(0.7-3.2 \%)$, marinas $(0.25-0.65 \%)$ and economic productivity $(2.9-6.9 \%)$ for all of New Zealand's urban centres examined and with considerable ranges between low and high growth-scenario predictions. Expected annual population growth was usually positive (averaging $0.5 \%$ across regions, with a maximum of $1.9 \%$ for Auckland) but low- and moderate-growth scenarios predicted population declines of up to $0.1-0.9 \%$ p.a. (predicted annual growth rate) for some areas on the North Island's east and the South Island's west coasts (Table 2 and Supplementary Data 1). All the information utilized for model and forecast development was issued before the onset of the COVID-19 pandemic.
Relationships between coastal hardening and NIS occurrence. We used linear regression analysis to examine potential associations between the degree of coastal hardening (cumulative extent of all infrastructure types mapped) and the number of marine NIS occurring around coastal urban centres in our case study region. Validated datasets from government-funded national baseline and target surveillance programmes (2001 to ongoing) provided the number of non-indigenous marine species reported from 12 of the 14 New Zealand model locations in 2018 (ref. ${ }^{60}$ ) (Supplementary Data 1). These numbers were regressed on the extent (linear $\mathrm{km}$ ) of coastal hardening associated with each of the 12 locations

We then applied the derived relationship between coastal hardening and NIS occurrence to the predicted regional increases in coastal hardening (25-year timeframe, see above). This provided estimates of the number of new/additional NIS that might be expected for each of the New Zealand locations given the predicted increases in coastal hardening. It was not our intention to use this relationship to make empirical predictions of the likely emergence of new NIS Instead, we wanted to explore any correspondence of these results to recent quantitative risk modelling commissioned by the New Zealand government that examined the relative importance of New Zealand coastal centres as recipients of new NIS based on shipping patterns and associated transport of organisms in ballast water and via hull fouling ${ }^{33}$. We thus ranked our case study locations in accordance with: (1) their relative contribution to the total predicted increase in domestic coastal hardening (New Zealand-wide by 2043; Fig. 3), (2) the number of new NIS expected based on the regression equation and our coastal hardening forecasts and (3) each centre's 'biosecurity risk score' (ranked) derived from the risk models by Hatami et al. ${ }^{33}$. We then examined the correspondence of regional rankings according to (1), (2) and (3) to assess how our predictions compare with a sophisticated biosecurity risk analysis based on biofouling and ballast water discharge models.

Reporting Summary. Further information on research design is available in the Nature Research Reporting Summary linked to this article.

\section{Data availability}

All data collected and analysed during this study are included in the Supplementary Information and a spatial geodatabase available at https://github.com/ofloerl/ Coastal-Hardening.

\section{Code availability}

No custom computer code or algorithm was used to generate results. The software environment $\mathrm{R}$ was used for all data exploration, statistical analyses and model development described in this manuscript using freely available $\mathrm{R}$ packages. The $\mathrm{R}$ workflow is at https://github.com/ofloerl/Coastal-Hardening.

Received: 3 March 2021; Accepted: 4 September 2021; Published online: 21 October 2021

\section{References}

1. Dugan, J., Airoldi, L., Chapman, G. \& Walker, S. in Treatise on Estuarine and Coastal Science Vol. 8 (eds Wolanski, E. \& McLusky, D.) 17-41 (2011).

2. Bugnot, A. B. et al. Current and projected global extent of marine built structures. Nat. Sustain. 4, 33-41 (2020).

3. Connell, S. D. Floating pontoons create novel habitats for subtidal epibiota. J. Exp. Mar. Biol. Ecol. 247, 183-194 (2000).

4. Glasby, T., Connell, S., Holloway, M. \& Hewitt, C. Nonindigenous biota on artificial structures: could habitat creation facilitate biological invasions? Mar. Biol. 151, 887-895 (2007).

5. Heery, E. C. et al. Identifying the consequences of ocean sprawl for sedimentary habitats. J. Exp. Mar. Biol. Ecol. 492, 31-48 (2017).

6. Scherner, F. et al. Coastal urbanization leads to remarkable seaweed species loss and community shifts along the SW Atlantic. Mar. Pollut. Bull. 76, 106-115 (2013)

7. Malerba, M. E., White, C. R. \& Marshall, D. J. The outsized trophic footprint of marine urbanization. Front. Ecol. Environ. 17, 400-406 (2019).

8. Dafforn, K. A., Glasby, T. M. \& Johnston, E. L. Comparing the invasibility of experimental "reefs" with field observations of natural reefs and artificial structures. PLoS ONE 7, e38124 (2012).

9. Airoldi, L., Turon, X., Perkol-Finkel, S. \& Rius, M. Corridors for aliens but not for natives: effects of marine urban sprawl at a regional scale. Divers. Distrib. 21, 755-768 (2015).

10. Hayes, K. R., Inglis, G. J. \& Barry, S. C. The assessment and management of marine pest risks posed by shipping: the Australian and New Zealand experience. Front. Mar. Sci. https://doi.org/10.3389/fmars.2019.00489 (2019).

11. Floerl, O., Inglis, G., Dey, K. L. \& Smith, A. The importance of transport hubs in stepping-stone invasions. J. Appl. Ecol. 46, 37-45 (2009).

12. Kaluza, P., Kolzsch, A., Gastner, M. T. \& Blasius, B. The complex network of global cargo ship movements. J. R. Soc. Interface 7, 1093-1103 (2010). 
13. Aguirre, D. et al. Loved to pieces: toward the sustainable management of the Waitematā Harbour and Hauraki Gulf. Reg. Stud. Mar. Sci. 8, 220-233 (2016).

14. Molnar, J. L., Gamboa, R. L., Revenga, C. \& Spalding, M. D. Assessing the global threat of invasive species to marine biodiversity. Front. Ecol. Environ. 6 485-492 (2008).

15. Seto, K. C., Güneralp, B. \& Hutyra, L. R. Global forecasts of urban expansion to 2030 and direct impacts on biodiversity and carbon pools. Proc. Natl Acad. Sci. USA 109, 16083-16088 (2012).

16. Neumann, B., Vafeidis, A. T., Zimmermann, J. \& Nicholls, R. J. Future coastal population growth and exposure to sea-level rise and coastal flooding-a global assessment. PLoS ONE 10, e0118571 (2015).

17. Kulp, S. A. \& Strauss, B. H. New elevation data triple estimates of global vulnerability to sea-level rise and coastal flooding. Nat. Commun. 10, 4844 (2019).

18. Lombard, A. T. et al. Practical approaches and advances in spatial tools to achieve multi-objective marine spatial planning. Front. Mar. Sci. https://doi. org/10.3389/fmars.2019.00166 (2019).

19. Pelling, M. \& Blackburn, S. Megacities and the Coast: Risk, Resilience and Transformation (Routledge, 2013).

20. Sutton-Grier, A. E., Wowk, K. \& Bamford, H. Future of our coasts: the potential for natural and hybrid infrastructure to enhance the resilience of our coastal communities, economies and ecosystems. Environ. Sci. Policy 51, 137-148 (2015).

21. Keller, R., Drake, J., Drew, M. \& Lodge, D. Linking environmental conditions and ship movements to estimate invasive species transport across the global shipping network. Divers. Distrib. 17, 93-102 (2011).

22. How Can We Meet Increasing Demand for Ports in the Upper North Island? A Report for the Upper North Island Strategic Alliance (PricewaterhouseCoopers, 2012).

23. Ernst \& Young Port Future Study. A Report Prepared for Auckland Council (Auckland Council, 2016).

24. NZIER Bigger Ships-Past, Present and Future Implications for New Zealand Supply Chains (New Zealand Economic Research Institute, 2017).

25. Hino, M., Belanger, S. T., Field, C. B., Davies, A. R. \& Mach, K. J. High-tide flooding disrupts local economic activity. Sci. Adv. 5, eaau2736 (2019).

26. United Nations Review of Maritime Transport 109 (United Nations Conference on Trade and Development, 2019).

27. Ferrario, F., Iveša, L., Jaklin, A., Perkol-Finkel, S. \& Airoldi, L. The overlooked role of biotic factors in controlling the ecological performance of artificial marine habitats. J. Appl. Ecol. 53, 16-24 (2016).

28. Firth, L. et al. Ocean sprawl: challenges and opportunities for biodiversity management in a changing world. Oceanogr. Mar. Biol. 54, 189-262 (2016).

29. Mayer-Pinto, M. et al. Functional and structural responses to marine urbanisation. Environ. Res. Lett. 13, 014009 (2018).

30. Bannister, J., Sievers, M., Bush, F. \& Bloecher, N. Biofouling in marine aquaculture: a review of recent research and developments. Biofouling 35, 631-648 (2019).

31. Colautti, R. I., Bailey, S. A., van Overdijk, C. D. A., Amundsen, K. \& MacIsaac, H. J. Characterised and projected costs of nonindigenous species in Canada. Biol. Invasions 8, 45-59 (2006).

32. Mazur, K., Bath, A., Curtotti, R. \& Summerson, R. An Assessment of the Non-market Value of Reducing the Risk of Marine Pest Incursions in Australia's Waters (Australian Bureau of Agricultural and Resource Economics and Sciences, 2018).

33. Hatami, R. et al. Improving New Zealand's Marine Biosecurity Surveillance Programme Biosecurity New Zealand Technical Paper No. 2021/01 (Ministry for Primary Industries, 2021).

34. Sardain, A., Sardain, E. \& Leung, B. Global forecasts of shipping traffic and biological invasions to 2050. Nat. Sustain. 2, 274-282 (2019).

35. Monios, J., Bergqvist, R. \& Woxenius, J. Port-centric cities: the role of freight distribution in defining the port-city relationship. J. Transp. Geogr. 66 53-64 (2018).

36. The Ocean Economy in 2030 (Organisation for Economic Co-operation and Development, 2016).

37. Halpern, B. S. et al. Recent pace of change in human impact on the world's ocean. Sci. Rep. 9, 11609 (2019).

38. Dafforn, K. A. et al. Marine urbanization: an ecological framework for designing multifunctional artificial structures. Front. Ecol. Environ. 13, 82-90 (2015).

39. Diggon, S. et al. The marine plan partnership: Indigenous community-based marine spatial planning. Mar. Policy https://doi.org/10.1016/j. marpol.2019.04.014 (2019).

40. Noble, M. M., Harasti, D., Pittock, J. \& Doran, B. Understanding the spatial diversity of social uses, dynamics, and conflicts in marine spatial planning. J. Environ. Manag. 246, 929-940 (2019).

41. Abhinav, K. A. et al. Offshore multi-purpose platforms for a blue growth: a technological, environmental and socio-economic review. Sci. Total Environ. 734, 138256 (2020).
42. Jacob, C., Buffard, A., Pioch, S. \& Thorin, S. Marine ecosystem restoration and biodiversity offset. Ecol. Eng. 120, 585-594 (2018).

43. Hopkins, G. A. et al. Continuous bubble streams for controlling marine biofouling on static artificial structures. PeerJ 9, e11323 (2021).

44. Vucko, M. J. et al. Cold spray metal embedment: an innovative antifouling technology. Biofouling 28, 239-248 (2012).

45. Atalah, J., Newcombe, E. M., Hopkins, G. A. \& Forrest, B. M. Potential biocontrol agents for biofouling on artificial structures. Biofouling 30, 999-1010 (2014).

46. Airoldi, L. et al. Emerging solutions to return nature to the urban ocean. Ann. Rev. Mar. Sci. 13, 445-477 (2021).

47. Keeley, N., Wood, S. A. \& Pochon, X. Development and preliminary validation of a multi-trophic metabarcoding biotic index for monitoring benthic organic enrichment. Ecol. Indic. 85, 1044-1057 (2018).

48. Zaiko, A., Pochon, X., Garcia-Vazquez, E., Olenin, S. \& Wood, S. A. Advantages and limitations of environmental DNA/RNA tools for marine biosecurity: management and surveillance of non-indigenous species. Front. Mar. Sci. https://doi.org/10.3389/fmars.2018.00322 (2018).

49. Cristescu, M. E. Can environmental RNA revolutionize biodiversity science? Trends Ecol. Evol. 34, 694-697 (2019).

50. Chakravarthy, K., Charters, F. \& Cochrane, T. The impact of urbanisation on New Zealand freshwater quality. Policy Q. 15, 17-21 (2019).

51. Gittman, R. K. et al. Engineering away our natural defenses: an analysis of shoreline hardening in the US. Front. Ecol. Environ. 13, 301-307 (2015).

52. Hume, T. M., Snelder, T., Weatherhead, M. \& Liefting, R. A controlling factor approach to estuary classification. Ocean Coast. Manag. 50, 905-929 (2007).

53. Breiman, L. Random forests. Mach. Learn. 45, 5-32 (2001)

54. Prasad, A. M., Iverson, L. R. \& Liaw, A. Newer classification and regression tree techniques: bagging and random forests for ecological prediction. Ecosystems 9, 181-199 (2006).

55. Olden, J. D., Lawler, J. J. \& Poff, N. L. Machine learning methods without tears: a primer for ecologists. Q. Rev. Biol. 83, 171-193 (2008).

56. Kursa, M. B. \& Rudnicki, W. R. Feature selection with the boruta package. J. Stat. Softw. 36, 1-13 (2010).

57. Zuur, A. F., Leno, E. N. \& Elphick, C. S. A protocol for data exploration to avoid common statistical problems. Methods Ecol. Evol. 1, 3-14 (2010).

58. Liaw, A. \& Wiener, M. Classification and regression by randomForest. $R$ News 2, 18-22 (2002)

59. Kuhn, M. et al. caret: Classification and Regression Training (CRAN, 2019); https://CRAN.R-project.org/package $=$ caret

60. Ministry for the Environment \& Stats NZ. New Zealand's Environmental Reporting Series: Environment Aotearoa 2019 (Ministry for the Environment, 2019).

\section{Acknowledgements}

This research was funded by New Zealand Ministry for Business, Innovation and Employment research grants C01X1511 (O.F.) and CAWX1904 (O.F.) and internal resources provided by the authors' institutions. We thank D. Lohrer (National Institute of Water and Atmospheric Research) for access to the Coastal Explorer estuary classification database, A. Growcott (New Zealand Ministry for Primary Industries) for access to government biosecurity risk modelling and P. South (Cawthron Institute) for valuable feedback on an earlier version of the manuscript

\section{Author contributions}

O.F. led the development of the original concept of this manuscript, with assistance from all co-authors. M.C. and L.F. led the development and implementation of spatial mapping and analysis. J.A. and R.M. led the development of analytical pipelines. O.F. and M.C. led the data-gathering effort. O.F., R.M., A.B.B., K.A.D. and A.Z. led the preparation of the manuscript.

\section{Competing interests}

The authors declare no competing interests.

\section{Additional information}

Supplementary information The online version contains supplementary material available at https://doi.org/10.1038/s41893-021-00780-w.

Correspondence and requests for materials should be addressed to Oliver Floerl. Peer review information Nature Sustainability thanks the anonymous reviewers for their contribution to the peer review of this work.

Reprints and permissions information is available at www.nature.com/reprints.

Publisher's note Springer Nature remains neutral with regard to jurisdictional claims in published maps and institutional affiliations.

(c) The Author(s), under exclusive licence to Springer Nature Limited 2021 


\section{Reporting Summary}

Nature Research wishes to improve the reproducibility of the work that we publish. This form provides structure for consistency and transparency in reporting. For further information on Nature Research policies, see our Editorial Policies and the Editorial Policy Checklist.

\section{Statistics}

For all statistical analyses, confirm that the following items are present in the figure legend, table legend, main text, or Methods section.

n/a Confirmed

$\square$ The exact sample size $(n)$ for each experimental group/condition, given as a discrete number and unit of measurement

$\square$ \ A statement on whether measurements were taken from distinct samples or whether the same sample was measured repeatedly

The statistical test(s) used AND whether they are one- or two-sided

$\square$ Only common tests should be described solely by name; describe more complex techniques in the Methods section.

$\square$ \ A description of all covariates tested

$\square$ \ A description of any assumptions or corrections, such as tests of normality and adjustment for multiple comparisons

$\square$ A full description of the statistical parameters including central tendency (e.g. means) or other basic estimates (e.g. regression coefficient)

$\bigotimes$ AND variation (e.g. standard deviation) or associated estimates of uncertainty (e.g. confidence intervals)

$\varnothing$ For null hypothesis testing, the test statistic (e.g. $F, t, r$ ) with confidence intervals, effect sizes, degrees of freedom and $P$ value noted Give $P$ values as exact values whenever suitable.

Х $\square$ For Bayesian analysis, information on the choice of priors and Markov chain Monte Carlo settings

Х $\square$ For hierarchical and complex designs, identification of the appropriate level for tests and full reporting of outcomes

Х $\square$ Estimates of effect sizes (e.g. Cohen's $d$, Pearson's $r$ ), indicating how they were calculated

Our web collection on statistics for biologists contains articles on many of the points above.

\section{Software and code}

Policy information about availability of computer code

Data collection Coastal mapping was undertaken using ArcGIS Pro (version 2.4.0) and based on satellite and aerial imagery from Land Information New Zealand's (LINZ) imagery basemaps, ESRI's World Imagery (2014-2018; DigitalGlobe, councils and Maine GeoLibrary). All shapefiles have been stored on GitHub and a link is provided in the manuscript file.

Data analysis All exploratory and statistical analyses were undertaken in the programming software R (v 3.6.2). Data summaries from ArcGIS Pro were imported as .csv or .xls files and converted to .r dataframes. Basic data summaries were developed using RStudio and published packages such as Tidyverse, Ggplot2 and Dplyr. More complex analyses were carried out with the packages Boruta and randomForest. All code (annotated) is stored on GitHub and a link is provided in the manuscript file.

For manuscripts utilizing custom algorithms or software that are central to the research but not yet described in published literature, software must be made available to editors and reviewers. We strongly encourage code deposition in a community repository (e.g. GitHub). See the Nature Research guidelines for submitting code \& software for further information.

\section{Data}

Policy information about availability of data

All manuscripts must include a data availability statement. This statement should provide the following information, where applicable:

- Accession codes, unique identifiers, or web links for publicly available datasets

- A list of figures that have associated raw data

- A description of any restrictions on data availability

All data generated or analysed during this study have been made available on the repository GitHub. A link is provided in the manuscript file. 


\section{Field-specific reporting}

Please select the one below that is the best fit for your research. If you are not sure, read the appropriate sections before making your selection.

\section{Ecological, evolutionary \& environmental sciences study design}

All studies must disclose on these points even when the disclosure is negative.

Study description

We quantified coastal hardening (the linear extent [km] of formerly natural coastline that has become replaced by built urban and industrial infrastructure) associated with 30 coastal urban centres around New Zealand, Australia, North America and the United Kingdom. Our objective was the development of a predictive model to enable regional-scale forecasts of future expansions in coastal infrastructure - and the development of strategies to mitigate the associated ecological, social and cultural impacts. Using non-linear modelling approaches, and starting out with a set of 25 candidate explanatory variables, we identified a predictive model that explains present-day extent of coastal hardening on the basis of eight predictors associated with regional population size/growth, gross domestic product, shipping and trade, boating activity and geomorphological characteristics. Using New Zealand as a casestudy, we apply this model to existing government and industry predictions regarding population, tourism and trade (low, moderate and high growth scenarios) and derive a 25-year forecast for the potential spread of coastal infrastructure around New Zealand's coastal regions. The model can applied to other areas of the world.

Research sample

Study locations: we chose a total of 30 urban centres from New Zealand, Australia, North America and the United Kingdom. The centres had wide size ranges (10,000 - 2.8 million inhabitants), and were located in a wide size range of harbours or estuaries (16 $505 \mathrm{~km}$ coastline length). They also spanned wide ranges in other physical, demographic or economic characteristics. This wide range and global distribution was ensured to: (1) maximise global application of our model, and (2) since we chose New Zealand as a casestudy location for application of the model we needed to ensure that global model locations included - and exceeded - the range of predictors applying to the New Zeland locations. With regard to the generation of regional and domestic forecasts (to 2043), the best available growth predictions from government agencies, national statistical departments, maritime and financial industry and published literature were utilised. In many cases this involved white/technical/non-peer reviewed reports, datasets and literature but this was unavoidable. All sources are identified in the Supplementary Information.

Sampling strategy We focused our study on urban centres associated with coastal harbours and estuaries, or protected by coastal islands. This was done (1) to standardize the general environmental settings as far as possible and (2) because most - but not all - global urban centres were originally and deliberately established in such locations due to the sheltered conditions (from swell, storms) they provide. As stated above, we needed to ensure that our sample size included centres that spanned and exceeded the ranges in key predictor and response variables associated with our case-study locations. This influenced the choice of sampling locations both small (e.g. Nainamo, Canada) and large (e.g. Baltimore, US, and Vancouver, Canada). A further consideration in the choice of sampling locations was the availability of reliable predictor data (e.g. GDP, shipping and boating traffic, trade volume and growth, population size/ growth, demographic/population size and growth) and the need for the range in these predictors to span and exceed those of the case-study locations. Prior to confirming a sampling location we undertook searches for relevant published literature, government or industry reports, financial predictions and, where necessary, made contact with regulatory agencies, port/marine companies, and other organisations to ascertain the availability of critical data. We capped our study at a sample size of 30 global urban centres. This was done for two reasons. First, they ranged from a population size of $<20,000$ inhabitants to nearly 3 million inhabitats, with similar ranges in physical size and trade / shipping related dimensions. This was regarded as a representative of most global coastal centres acknowledging that it was restricted to urban centres associated with English-speaking countries. The locations did not include coastal mega-centres around India, China or South East Asia, in part due to challenges with predictor data availability. Second, the effort required for detailed GIS mapping and collation of predictor data was substantial, requiring up to 2 weeks of full-time effort per location. We strived to use our available resources in a way that maximised the number of global locations we were able to examine. Our resulting dataset of coastal hardening (categorised into infrastructure types) in 30 global locations is, as far as we know, the first of its kind and calibre.

Data collection

Mitchell Chandler and Lisa Floerl obtained New Zealand and global coastal GIS maps and (for New Zealand) bathymetric maps. The entire coastline associated with each urbanised harbour/estuary was then examined, to the level of individual jetties and pontoon berths (i.e at a scale of 1-10 metres). This was the highest resolution practicable (given some harbours have coastlines of $>400 \mathrm{~km}$ ) and resulted in a unique, high-quality and accurate dataset. Oliver Floerl, Mitchell Chandler and Rob Major collected the predictor data for all mapped locations using literature and internet searches (maritime industry, national/regional regulatory authorities and statistical departments, personal communication with marina and port operators, economic consultancies and other sources). The data were checked for possible outliers or reporting errors and then developed into a predictor dataframe. Oliver Floerl collected information on the number of non-indigenous species established around the urban centres associated with our case-study region (New Zealand), using information obtained from a national reporting database developed by the NZ Government (Ministry for Primary Industries) and latest environmental reporting from the Ministry for the Environment. Oliver Floerl also collected the input data (predictor values) for the 25-year forecast, via publications and other resources obtained from government departments, port/ shipping/marina industries, economic consultancies and other agencies. The exact sources are listed in the Supplementary Information. 
Data exclusions

Reproducibility

Randomization

Blinding
No data were excluded from the analyses.

Our study is fully reproducible. The collection of all predictor and response variable datasets is referenced (literature sources) and available as dataframes or GIS shapefiles. All exploratory and statistical analyses and model-building were undertaken in R and annotated scripts will be stored in a publicly available online repository.

This study did not include randomisation. The coastal urban centres selected for mapping and model development were selected from a larger global pool of coastal centres based on two key criteria: (1) associated with sheltered coastal harbours and estuaries, or protected by coastal islands. This was done to exclude extreme confounding influences arising from the presence of contrasting location-specific factors (e.g. a small minority of coastal centres are established right on the coast but at an elevated position on top of sea cliffs or similar, and those do not have the same need for coastal engineering and infrastructure as those at sea-level and located in sheltered and more erosion-prone harbours (i.e., the majority)). (2) Availability of high-quality, reliable predictor variable data. Several coastal centres in our initial 'potential target list' had to be omitted from mapping due to the unavailability of information pertaining to critical predictor variables.

Blinding was not possible or highly relevant to our study, which was focused on the examination of spatial GIS maps and collation of economic, social, demographic and industry-specific predictor information. However, mapping of the 30 global centres was undertaken in a near-random fashion, so that there was no clear sequence of mapping based on geographic region or the physical size of target locations.

Did the study involve field work? $\square$ Yes $\square$ No

\section{Reporting for specific materials, systems and methods}

We require information from authors about some types of materials, experimental systems and methods used in many studies. Here, indicate whether each material, system or method listed is relevant to your study. If you are not sure if a list item applies to your research, read the appropriate section before selecting a response.

Materials \& experimental systems

\begin{tabular}{|c|c|}
\hline $\mathrm{n} / \mathrm{a}$ & Involved in the study \\
\hline Х & $\square$ Antibodies \\
\hline Х & $\square$ Eukaryotic cell lines \\
\hline$\sqrt{2}$ & $\square$ Palaeontology and archaeology \\
\hline$\bigotimes$ & $\square$ Animals and other organisms \\
\hline Х & $\square$ Human research participants \\
\hline$\bigotimes$ & $\square$ Clinical data \\
\hline 凶 & $\square$ Dual use research of concern \\
\hline
\end{tabular}

\begin{tabular}{l|l}
\multicolumn{2}{l}{ Methods } \\
\hline n/a & Involved in the study \\
$\bigotimes$ & $\square$ ChIP-seq \\
$\bigotimes$ & $\square$ Flow cytometry \\
$\square$ & $\square$ MRI-based neuroimaging
\end{tabular}

